\title{
The challenge of incorporating animal welfare in a social life cycle assessment model of European chicken production
}

\author{
Craig W. Tallentire ${ }^{1}$ (D) $\cdot$ Sandra A. Edwards ${ }^{1} \cdot$ Tommy Van Limbergen $^{2} \cdot$ Ilias Kyriazakis $^{1}$
}

Received: 25 May 2018 / Accepted: 20 November 2018 / Published online: 30 November 2018

(C) The Author(s) 2018

\begin{abstract}
Purpose There is increasing public concern over standards of farm animal welfare, yet the majority of sustainability studies of livestock have thus far focused only on environmental performance and profitability. Where social analysis has been carried out, there has yet to be a consistent methodology developed that incorporates animal welfare into social life cycle assessment (S-LCA). A framework was developed to assess animal welfare, using conventional broiler chicken meat production in Europe as a case in point. Methods Data were collected on stocking density, mortality, and carcass condemnation rate from conventional chicken meat production systems in Europe. The quantitative risk of each welfare indicator was characterised in accordance with the Social Hotspots Database methodology based on best to worst farm performances, i.e. quartiles of the data collected for each indicator. The overall animal welfare impact was assessed using a weighted sum methodology, which accounted for the level of risk animals were exposed to for each indicator and the animal lifespan. From this, a Social Hotspot Index (SHI) could be calculated for the animal welfare impact associated with the functional unit, which was $1 \mathrm{~kg}$ of chicken meat production. The animal welfare impact of four European countries was then compared.

Results and discussion The countries assessed displayed a range of values for overall animal welfare impact; the country with the best animal welfare had a SHI for animal welfare impact of 0.14, whilst the worst had a SHI for animal welfare impact of 0.72 . Farms that kept more birds per building had an increased overall animal welfare impact. Animal welfare, determined by negative welfare indicators, was worse in more recently established farm buildings due to increased flock size.

Conclusions A methodology that incorporates animal welfare indicators into S-LCA was developed that is both scalable and related to welfare assessment frameworks. Although only some specific negative welfare indicators were considered here, the methodology could easily accommodate additional negative indicators and even positive welfare indicators as advancements are made in the understanding of animal welfare. Hence, this study provides a springboard for further development of S-LCA, animal welfare assessment and, ultimately, improved animal welfare in livestock systems.
\end{abstract}

Keywords Animal welfare $\cdot$ Broiler chicken $\cdot$ Livestock $\cdot$ Social life cycle assessment $\cdot$ Sustainability

\section{Introduction}

For a production system to be sustainable, it should be economically viable, contribute to the equitable management of

Responsible editor: Marzia Traverso

Craig W. Tallentire

c.w.tallentire@newcastle.ac.uk

1 Agriculture, School of Natural and Environmental Sciences, Newcastle University, Newcastle upon Tyne NE1 7RU, UK

2 Department of Reproduction, Obstetrics and Herd Health, Faculty of Veterinary Medicine, Ghent University, 9820 Merelbeke, Belgium resources, be embedded in its socio-cultural context, and be respectful towards both humans and non-human animals (henceforth referred to simply as "animals") (Broom et al. 2013; Dolman et al. 2014). As a growing proportion of society is becoming sensitive to the way animals are reared, consumers are beginning to demand more humane treatment of livestock and, as a result, animal welfare is becoming a major issue for the agri-food sector (Carenzi and Verga 2009; European Commission 2005, 2017). Animal welfare is the health and well-being of animals and characterised by a concern that the way in which humans treat animals can cause the animals physical and mental suffering. In agricultural systems, where the environment is restricted, animals are often less able to carry out the actions that would reduce suffering (Dawkins 
1990). A widely used framework for the practical assessment of animal welfare is that of the "Five Freedoms"; these are: freedom from hunger and thirst; freedom from discomfort; freedom from pain, injury, and disease; freedom to express normal behaviour; and freedom from fear and distress (FAWC 1979, 2009).

Although chicken meat is expected soon to become the most consumed animal protein globally (Alexandratos and Bruinsma 2012; FAO 2016; Kearney 2010), it is often shown to be the animal protein with the highest associated animal welfare concerns (Clark et al. 2016; Lamey 2007). There are concerns about the space in which the birds are raised, the enrichment of their environment or lack thereof, and their ability to express normal behaviour. Furthermore, production diseases associated with animal welfare (e.g. leg problems, contact dermatitis, ascites, and sudden death syndrome) have been exacerbated by selection pressures for fast growth rate and increased feed efficiency placed on the birds over recent decades (EFSA Panel on Animal Health and Welfare 2010; Fraser et al. 2013). There are many important interactions between bird genotype and the environmental inputs, such as feeding regime and bird management, which can influence the animal welfare experienced in practice (Bessei 2006; Buyse et al. 2007).

Although there is recognition of the need to account for the social sustainability of livestock systems, few studies have considered animal welfare as a social dimension (Broom 2010; Llonch et al. 2015; Neugebauer et al. 2014). Studies that have included animal welfare indicators within the methodology have mainly focused on the dairy industry (Meul et al. 2012; van Asselt et al. 2015; Zucali et al. 2016), with only two studies having exclusively focused on broiler chicken systems (Bokkers and de Boer 2009; Castellini et al. 2012). However, no study thus far has incorporated animal welfare into a social life cycle assessment (S-LCA) in a way that is both scalable and related to welfare assessment frameworks, whilst also adhering to basic LCA principles. The aim of this study was to address this by identifying methodological issues associated with incorporating animal welfare into S-LCA and to develop a novel framework to do so, applying it to conventional chicken meat production systems in Europe as a case in point. Several welfare-related indicators were applied to characterise the sector specific animal welfare risks on farms in Europe in relation to the Five Freedoms.

\section{Methodological issues}

Animal welfare has largely been neglected in S-LCA studies of agricultural systems because animals have not been assigned an impact category or subcategory under any stakeholder group, nor have any assessment criteria been formally identified (Notarnicola et al. 2017). According to the UNEP-
SETAC (2009) Life Cycle Initiative, S-LCA inventory data and impact assessment categories must be specified in relation to the following stakeholder groups: the workforce, the local community, the consumers, value chain actors, and society. It is debatable how adequately each of these established stakeholder groups can represent the interests of animals, as discussed in Box 1. In this study, an individual social impact category has been developed to assess animal welfare; this methodology can easily be adopted into any stakeholder group in the future should animals be acknowledged in an official framework.

Where animal welfare indicators have been incorporated into S-LCA studies, the methodology by which animal welfare is assessed ranges from simply checking that employee training in good welfare practices has been provided (Revéret et al. 2015), to more sophisticated multicriteria decision analysis approaches that incorporate indicators such as kinetic activity level, animal injury, and stress level (Bokkers and de Boer 2009; Castellini et al. 2012). Methodologies that rely on time-consuming data collection, such as in the latter case, cannot easily be applied to an S-LCA framework on a large

Box 1 Examples of stakeholder groups which could represent animals in a future framework and some shortcomings

First example: the workforce.

Although it is true that outside of captivity, animals fall victim to predators, disease, and exposure to climatic extremes, the conditions in which livestock are raised are under human control. Neugebauer et al. (2014) suggest that this custodianship aligns livestock with the workforce as the most obvious stakeholder group. However, animals are not classed as workers per se, and combining human work hours and the time in which animals are exposed to certain risks is not practicable when quantifying impact. Furthermore, the needs of human workers and livestock are very different, thus it is unlikely the animals will be sufficiently represented by the workforce.

Second example: consumers/citizens.

This follows the assumption that animal welfare is subjective and defined by the experience of the "customer" (Broom 2010; de Jonge and van Trijp 2013; Te Velde et al. 2002). However, as was the case with the first example, animals have a uniquely different relationship with the production system to consumers; the animals are the product. Animal welfare should be seen as independent of the empathy of individuals and therefore consumer judgement or value choices may not adequately represent the animal's interests. The society stakeholder group has similar constraints and has only been proposed to cover ethical impacts at a societal level, e.g. conflict, legal system fragility, and corruption.

Third example: value chain actors.

Animals cannot express their concerns without the inputs of an invested third party (Compassion in World Farming 2017); hence, animal welfare may more easily fit in the value chain actors group, akin to promoting social responsibility.

Fourth example: animals.

Alternatively, animals could be classified into their own stakeholder group. However, Neugebauer et al. (2014) argue that defining livestock in this way could lead to inconsistencies with existing stakeholder groups, pointing out the fact children are not defined as a separate group, but as a subcategory. 
scale. "Iceberg indicators" may present a convenient compromise for evaluating the welfare performance of a farm (Wathes 2010), especially when the data required are usually collected as standard practice, e.g. bird mortality or carcass condemnation (see Sect. 3.3).

The data collected in animal welfare assessments for each indicator are often expressed on an ordinal scale, which limits the use of weighted sums to aggregate them (Botreau et al. 2007a, b). In S-LCA, ranking systems that employ qualitative and semi-qualitative based assessment tools and relative scores may be applied (Del Prado et al. 2011; Head et al. 2014). These scores are based on previous literature or expert opinion and therefore may be subjective and, at worst, do not adhere to basic LCA requirements, such as by acting independently of the functional unit (Box 2). Although in most cases the authors of S-LCA studies that consider animal welfare have attempted a logical characterisation methodology, e.g. determined by benchmarking farms via statistical analysis (Dolman et al. 2014) or by using welfare protocols (Meul et al. 2012; Scherer et al. 2018; Zucali et al. 2016), no consistent methodology has been developed between studies. This can make it difficult to compare different systems in terms of animal welfare assessment frameworks, especially when the systems are situated in different countries where social acceptability varies; as a social impact, animal welfare should not relate to cultural differences but to the biology of the species in question. To amend this, we have developed an alternative methodology whereby the risk of several animal welfare indicators has been characterised as part of a framework for assessing (at least in part) the animal welfare of broiler chickens across Europe.

Box 2 Examples of ill-suited welfare assessment criteria applied previously in S-LCA

First example: inappropriate welfare indicators.

In their proposed framework for assessing animal welfare, Scherer et al.

(2018) considered stocking density, the number of animals affected, the slaughter age, and "sentience level," determined by calculating the cortical neurons an animal has relative to humans, as indicators of animal welfare. They assumed that a less intelligent animal has less ability to suffer than a more intelligent animal. On the contrary, as pain is a primitive survival response, an animal with lower intelligence may require more intense pain in order to learn. Furthermore, following their framework's emphasis on the number of animals affected, insects had worse welfare than any other livestock despite having lower presumed sentience (Chan 2011); this does not reflect present societal concerns (Varner 2002).

Second example: welfare assessment is independent of the functional unit.

When animal welfare is determined using an ordinal scale to rate a farm and the number of animals or length of time the animals are affected on that farm is not considered, the animal welfare impact value associated with the product will always be the same regardless of the functional unit (e.g. Müller-Lindenlauf et al. 2010). Following this methodology, more or less product may be produced whilst the animal welfare impact value of the system remains unchanged.

\section{An alternative methodology}

\subsection{Goal, scope, and system boundary of the S-LCA}

The S-LCA methodology developed in this study was applied to chicken production as a case in point. The goal of the SLCA was to evaluate the differences in animal welfare impact of meat chicken production between four European countries. In doing so the associations between farm characteristics and animal welfare implications in European chicken production systems could be identified. Data were collected from conventional chicken meat production farms, i.e. climate-controlled (e.g. fan-ventilated), artificially lit indoor systems, which is the predominant chicken meat production system in Europe (Compassion in World Farming 2013). These data were used to: (1) inform the animal welfare assessment framework (Sect. 3.4) that was applied in this study and (2) assess the overall animal welfare impact associated with the functional unit of each farm.

The functional unit was the production of $1 \mathrm{~kg}$ of chicken meat. The system boundary of the study was limited to the chicken rearing and slaughter processes only; hence, all upstream processes associated with feed procurement, transportation, and resource use were excluded for the purpose of this study, although we acknowledge the boundary could be expanded to include upstream animal welfare issues in future SLCAs, e.g. animal derived proteins in the feed, pest control, habitat destruction, and roadkill. The research findings offer a context for developing options to improve the sustainability of chicken meat production systems and serve as a baseline for the future. Thus, the study was aimed at a scientific audience, particularly LCA practitioners and animal welfare experts, with policy makers as a secondary interest group.

\subsection{Data collection}

Data were collected from 358 conventional chicken meat production farms from across continental Europe. Information was provided on the characteristics of each farm, such as the total number of birds on the farm at one time (henceforth referred to as "farm size"), the number of buildings on the farm in which birds are reared, the average age of the farm buildings (henceforth referred to as "farm age"), and the amount of space on the farm dedicated to rearing chickens. Farms sampled varied vastly in size (9000-405,000 birds) and average building age (1-51 years). Further data were provided to determine the welfare indicators discussed in Sect. 3.3. On the request of the participating poultry companies and as agreed by the PROHEALTH consortium who collected the data, the country from which each set of data was gathered was not disclosed and was instead assigned a code. 


\subsection{Animal welfare indicators}

To assess animal welfare within a S-LCA framework, data were collected on stocking density, animal mortality, and carcass condemnation in the slaughter house from broiler chicken production systems across Europe. This information is recorded routinely by broiler chicken producers and integrators; thus, the indicators defined in this study can readily be incorporated into sustainability assessments and are more practical for use in future S-LCAs than those used in other studies of chicken production (Bokkers and de Boer 2009; Castellini et al. 2012). The indicators applied in this study are all negative, i.e. increased values relate to an increased animal welfare impact. Collectively, the animal welfare indicators reveal the farm animal welfare implications and at which part of the production process animal welfare may be improved, although other indicators could be included if data were available. The justification for each indicator and its relevance to animal welfare is discussed below.

Stocking density is defined by the total bird mass per square meter of rearing space at slaughter weight. Influencing welfare mainly via litter quality, air quality, pathogen transmission, and thermal stress, high stocking density has been associated with the increased prevalence of foot pad dermatitis, hock burn, breast blisters, soiled plumage, restricted locomotion, and panting (Allain et al. 2009; Bessei 2006; EFSA Panel on Animal Health and Welfare 2010; McLean et al. 2002). Thus, this indicator relates to the animals' freedom from discomfort and freedom from pain, injury, and disease (FAWC 2009). Increased stocking density can also encroach on the animals' freedom to express normal behaviour (FAWC 2009); restricting the normal behaviours that the birds can perform may lead to other behaviours that can be presumed to indicate the space restriction is distressing, e.g. jostling, disturbance of resting birds, and aggression (Bokkers et al. 2011; Buijs et al. 2011; Thomas et al. 2011). The ability to perform normal behaviours is considered to be an important aspect of welfare by the consumer stakeholder group (Clark et al. 2016).

Animal mortality included animals that had died without human intervention and those that were culled by farm workers and was comprised of early mortality, late mortality, and the birds that were dead on arrival at the slaughterhouse (DOA). High percentage mortality is presumed to be related to poor flock health and thus associated with the animals' freedom from pain, injury and disease (FAWC 2009; Haslam et al. 2008; Welfare Quality $\left.{ }^{\circledR} 2009\right)$. The early mortality was the total percentage of birds that died or were culled in the first 7 days on the farm. Late mortality included all on-farm fatalities that happened after the first week, but did not include the animals that died during transportation to the slaughter house. In many cases, birds are culled due to performance issues that may or may not be related to poor welfare. Around half of the birds culled on the grounds of animal welfare can be attributed to lameness (Gocsik et al. 2017), and this was confirmed elsewhere (Applied Group 2018; personal communication). The death of an individual bird is not necessarily a welfare problem; indeed, death may be seen as the ultimate welfare solution (Dawkins 1990). However, the way an animal dies can cause undue suffering especially from disease or injury. In this light, timely culling can reflect good attention to the wellbeing of animals. On the other hand, culling underperforming but otherwise healthy birds may be seen as unethical on the grounds of welfare and respect for animals and will lead to increased lives lost; the ideal situation regarding welfare is when culling is not needed (EFSA Panel on Animal Health and Welfare 2010; Gremmen et al. 2018). For practicality, the cause of death was not recorded in data utilised in this study.

DOA refers to the percentage of the flock that died in transit between the farm and the slaughterhouse. This has been widely acknowledged as an important indicator of animal welfare in numerous studies (Kittelsen et al. 2015; Nijdam et al. 2006; Petracci et al. 2006). It reflects the conditions experienced during transport, in combination with previous life factors affecting the stress-susceptibility of individual birds. Transporting birds from the farm to the slaughterhouse subjects them to animal welfare issues related to each of the Five Freedoms (FAWC 2009), due to levels of handling which they have not previously experienced, noise, vibration, thermal challenges, feed and water withdrawal, high stocking density, social disruption, and unfamiliar environments (EFSA Panel on Animal Health and Welfare 2010). A high percentage of birds DOA has been associated with increased body temperature, soiled plumage, and panting at the farm level (Jacobs et al. 2017); these are all indicators of animal stress that are not reported as standard by farms.

Finally, carcass condemnation refers to the number of birds that were rejected at the slaughter stage due to signs of disease or faecal contamination. Specifically, carcasses may have been rejected due to evidence of tumours (e.g. in the liver), septicaemia infection, ascites, airsacculitis, cellulitis, synovitis, or other signs of inflammation, bruising, and haemorrhaging (Allain et al. 2009; Gouveia et al. 2009; Lupo et al. 2008). These conditions are associated with poor welfare related to the Five Freedoms and will result in increased animal mortality in most instances. However, where birds survived to the slaughter stage, these conditions may have caused undue suffering; in particular, stress caused by loading and transport may exacerbate the symptoms and enhance the expression of clinical signs in animals suffering from a disease (Huneau-Salaün et al. 2014). Animal welfare indicators that can be measured post-mortem and which are strongly correlated with the climatic conditions within the farm building during rearing are seen by some as the most efficient way to organise controls and target potential problems with environmental conditions on the farm (European Commission 2018). Including carcass condemnation as a 
welfare indicator gives farms no incentive to keep birds alive that are experiencing welfare issues prior to slaughter. This is important, as the maximum stocking density a farm may achieve depends on mortality rate (European Commission 2007); if the on-farm mortality is too high, the stocking density of subsequent flocks must be reduced, and this is often perceived by farmers as a penalty. To stay below the limit and avoid such a reduction, birds that might otherwise have been culled may instead be transported for slaughter, so they are not included as part of the on-farm mortality rates (European Commission 2018). Carcasses may also be condemned due to inadvertent incorrect slaughter that can have animal welfare implications (e.g. live bird scalding). However, the slaughtering method was not considered important in this methodology from an animal welfare perspective as, provided the process is humane, it is not intrinsic to welfare assessment frameworks (FAWC 2009). Finally, increased carcass condemnation affects welfare via increasing the number of birds affected for the functional unit (Scherer et al. 2018).

\subsection{Assessment framework}

In this study, animal welfare was incorporated into the Social Hotspots Database (SHDB) methodology for carrying out an S-LCA developed by Benoit-Norris et al. (2012). The SHDB, built by New Earth in conjunction with an economic model derived from the Global Trade Analysis Project, is an overarching framework with a database designed to ease the data collection burden in S-LCA studies (Benoit-Norris et al. 2012, 2014; Pelletier et al. 2018). Following this methodology, each social indicator associated with a social impact category is assigned a quantified level of risk, which is then multiplied by the amount of time associated with the functional unit (Benoît-Norris et al. 2010, 2011).

The characterisation of animal welfare risks for meat chickens in Europe was based on the quartiles of the data collected for each indicator (Sect. 3.3): stocking density, early mortality, late mortality, DOA, and carcass condemnation. This is consistent with the S-LCA methodology developed by Benoit-Norris et al. (2015) where the risk levels assigned to the social indicators were based on the quartiles or obvious transitions of the data and defined as low, medium, high, and very high risk (Table 1). Hence, an indicator would be determined as being low risk if it had a value in the lower quartile of the sample data for that indicator, medium risk if it was in the second quartile, high risk if it was in the third quartile, and very high risk if it was in the upper quartile.

The levels of risk were weighted by a factor of $0.1,1,5$, and 10 for the low, medium, high, and very high risk, respectively (Benoît-Norris et al. 2015). These weightings were designed to represent the relative probability of an adverse situation to occur but may be changed in the future. Individual indictors may also receive different weightings depending on their importance; however, every indicator was regarded as equally important in this study. The animal "work hours," i.e. the collective hours (h) of life associated with the functional unit, were augmented depending on the level of risk throughout the system that was being assessed (Pelletier et al. 2018). To calculate the total hours associated with the functional unit, the birds that provided the meat, the birds that died in transit and the birds whose carcasses were rejected were associated with the total hours from hatch to slaughter weight. The on-farm mortalities were only associated with $50 \%$ of the time the birds were exposed to the risk of dying at each stage, because the exact time of death was not recorded. Since the weighted factor for medium risk had a value of 1 , medium risk was used as the reference when calculating the weighted sum for animal welfare impact (Eq. (1)). This is consistent with the SHDB methodology, i.e. every social impact category can be expressed in terms of medium risk hour equivalent (mrh eq.).

Animal welfare impact $[$ mrh eq. $]=\sum_{\mathrm{i}=1}^{\mathrm{n}}\left(T[\mathrm{~h}] * R_{\mathrm{i}} * W_{\mathrm{i}}\right)$

where:

$i \quad$ indicator, e.g. of animal welfare

$n \quad$ number of indicators, e.g. of animal welfare

$T$ Time, i.e. work hours

$R_{\mathrm{i}} \quad$ risk weighting factor associated with indicator

$W_{\mathrm{i}}$ indicator weighting (all indicators had a weighting of 1 in this study)

Finally, a Social Hotspot Index (SHI) may be calculated for the animal welfare impact (Benoit-Norris et al. 2012, 2015). This step is important, as the total value of the animal welfare impact (mrh eq.) will be changed if data for additional animal welfare indicators are collected and applied to the S-LCA. The value of the animal welfare impact also depends on the system efficiency; if birds grow faster but are slaughtered at the same age, and the risk level associated with every animal welfare indicator remains the same, then the system would have a lower animal welfare impact value associated with $1 \mathrm{~kg}$ of meat production despite the animal welfare being unchanged. The SHI for animal welfare impact resolves this, as the animal welfare of a system is calculated as a proportion of its maximum animal welfare impact, i.e. the potential weighted sum should the animals have been exposed to a very high risk for every animal welfare indicator (Eq. (2)). Whereby a SHI value of 1 would indicate the worst possible animal welfare for a given system. Each indictor may be also multiplied by an additional weighting factor $(W)$. As aforementioned, each indicator received an equal weighting in this study, but the methodology can easily be adapted to make individual indicators more or less important should the practitioner deem it appropriate to do so. Should no data be available for an indicator, e.g. for a specific farm or location, that indicator can be 
Table 1 Risk characterisation rules for animal welfare indicators at a sector level in Europe

\begin{tabular}{llllll}
\hline Level of risk & Early mortality $(\%)$ & $\begin{array}{l}\text { Late } \\
\text { mortality }(\%)\end{array}$ & $\begin{array}{l}\text { Dead on } \\
\text { arrival }(\%)\end{array}$ & $\begin{array}{l}\text { Condemned } \\
\text { carcasses }(\%)\end{array}$ & $\begin{array}{l}\text { Stocking } \\
\text { density }\left(\mathrm{kg} / \mathrm{m}^{2}\right)\end{array}$ \\
\hline Low risk & $<0.56$ & $<2.18$ & $<0.09$ & $<0.61$ & $<33.74$ \\
Medium risk & $0.56-0.91$ & $2.18-2.75$ & $0.09-0.14$ & $0.61-1.00$ & $33.74-39.59$ \\
High risk & $0.92-1.23$ & $2.76-3.34$ & $0.15-0.21$ & $1.01-1.60$ & $39.60-45.25$ \\
Very high risk & $>1.23$ & $>3.34$ & $>0.21$ & $>1.60$ & $>45.25$ \\
\hline
\end{tabular}

removed from the calculation (Benoit-Norris et al. 2015). This methodology can be used to assess any social impact category in the same way, and hence different social catergories can be combined to easily identify all the social hotspots within a system.

$S H I=\sum_{\mathrm{i}=1}^{\mathrm{n}}\left(T[\mathrm{~h}] * R_{\mathrm{i}} * W_{\mathrm{i}}\right) / \sum_{\mathrm{i}=1}^{\mathrm{n}}\left(T[\mathrm{~h}] * R_{\max } * W_{\mathrm{i}}\right)$

where:

SHI Social Hotspot Index, e.g. for animal welfare

$R_{\max }$ maximum risk weighting, i.e. very high risk $=10$

\subsection{Data analysis}

All correlations between the animal welfare indicators were weak except between DOA and carcass condemnation (Table 2), highlighting the importance of including each indicator when calculating the animal welfare impact. Whilst no relationship was seen here between on-farm mortality and DOA, in previous studies, a positive relationship between these two welfare indicators has been reported (Chauvin et al. 2011; Haslam et al. 2008). In contrast, a negative relationship was found by Jacobs et al. (2017); such an observation may indicate a greater emphasis on culling if animals are not "fit-for-transportation" (Jacobs et al. 2017). Culling birds in this way is arguably more humane than subjecting compromised animals to the ordeal of transit. This is reflected in our framework (Table 1), as one consequence of the methodology presented here is that more birds overall may die at the farm stage (late mortality), than may die in transit (DOA), before a farm may be ranked a higher level of risk for these corresponding welfare indicators. In addition, birds that die at the farm level are associated with less animal work hours than a bird that dies in transit accumulates. A strong positive relationship was identified between DOA and carcass condemnation, which tentatively suggests birds died in transit due to predisposing conditions that would also result in carcass condemnation. This justifies assigning the full lifetime to the birds DOA in the overall welfare calculation.

The farm characteristics (independent variables) were fitted in a univariate mixed model, i.e. the farm age, farm size, number of farm buildings (in which birds are reared), and the average number of birds per building (henceforth referred to as "flock size"). This was to test the effect of each farm characteristic on each welfare indicator and the overall animal welfare value. Variables with a $p$ value of $<0.20$ were retained for further analysis in a multivariable model (Van Limbergen et al. 2018). The correlations between the farm characteristics were assessed with bivariate Pearson correlation and were considered to be significant with a $p$ value $<0.05$. The multivariable model was constructed by using a forward and backward stepwise selection procedure, also including testing of two-way interactions of potentially significant main effects. As we were interested in correlations beyond the country effect, this was accounted for by always including country code as a fixed factor in the models. If more than one combination of independent variables were shown to have a significant effect on a dependent variable, the model with the best fit was reported. Normal probability tests and plots were examined to verify that the assumptions of normality and homoscedasticity of the residuals were fulfilled in the models. Finally, the differences between the countries for the overall welfare impact and the five indicators of welfare were analysed using analysis of variance (ANOVA) with Scheffe's method for post hoc comparison.
Table 2 Spearman correlation of animal welfare indicators

\begin{tabular}{lllll}
\hline Welfare indicator & Early mortality & Late mortality & Dead on arrival & Carcass condemnation \\
\hline Late mortality & $0.178^{*}$ & - & - & - \\
Dead on arrival & -0.118 & $0.296^{* *}$ & - & - \\
Carcass condemnation & -0.140 & $0.218^{* *}$ & $0.657^{* *}$ & - \\
Stocking density & -0.075 & 0.139 & 0.025 & 0.001 \\
\hline
\end{tabular}

* Significant correlation $(p \leq 0.05)$

** Significant correlation $(p \leq 0.01)$ 


\section{S-LCA results}

\subsection{The influence of farm characteristics on the animal welfare indicators}

The farm age and farm size were both significantly correlated with flock size ( $r=-0.530$ and 0.613 , respectively), but were not significantly correlated with each other. The number of farm buildings was significantly correlated with farm size only $(r=0.814)$. For late mortality, carcass condemnation, stocking density, and overall welfare, both farm age and flock size were retained in the multivariate model. Farm size was retained for stocking density and overall welfare. The number of farm buildings was retained for carcass condemnation and stocking density. Since farm size and the number of farm buildings were highly correlated, separate multivariate models were produced for stocking density to avoid issues of collinearity. No independent variable was retained for early mortality and DOA.

From the multivariate analysis, the farm age, the farm size, and the number of farm buildings were not significantly associated with any welfare indictor in this study, although there was a tendency for farm age to be negatively associated with late mortality (Table 3 ). The flock size was significantly associated with both carcass condemnation and stocking density. Finally, there was a significant association between the overall welfare impact of a farm and that farm's flock size. Hence, the more birds kept per building, the greater the animal welfare impact in the systems considered.

\subsection{Animal welfare impacts in four European countries}

The mean values of each animal welfare indicator and the overall welfare impact, along with the results of the analysis of the variance of countries A, B, C, and D are presented on Table 4. Country B had the lowest animal welfare impact per functional unit of the four countries, with a mean animal welfare impact of $3857 \mathrm{mrh}$ eq. per $1 \mathrm{~kg}$ production of chicken meat, giving country B a SHI for animal welfare impact of
0.14. Country B had a high risk of early mortality, medium risk of late mortality and stocking density, and a low risk of DOA and carcass condemnation.

Countries A and D had a SHI for animal welfare impact of 0.37 and 0.33 , respectively. Country A had a mean animal welfare impact of 9905 , and country D had a mean animal welfare impact of $9056 \mathrm{mrh}$ eq. per functional unit. Country A had a medium risk of early mortality and stocking density, a high risk of late mortality and DOA, and a very high risk of carcass condemnation. Country D had a high risk of early mortality, late mortality and stocking density, a medium risk of carcass condemnation, and a low risk of DOA. Thus, although having relatively similar animal impact values, the higher risk levels were concentrated at different parts of the production systems in the two countries.

Country $\mathrm{C}$ had the highest mean overall welfare impact, with a value of 19,894 mrh eq., determined by a very high risk of early mortality, late mortality and DOA, a high risk of carcass condemnation, and a medium risk of stocking density. Country $\mathrm{C}$ had a SHI for animal welfare impact of 0.72 , which was also the highest amongst the countries considered. Thus, animal welfare in country $\mathrm{C}$ was, on average, over five times worse than in country B when stocking density, mortality, and carcass condemnation were considered, and all indicators were of equal importance to animal welfare.

\section{Discussion}

Much research has focused on the environmental impact of livestock production; however, there have been relatively fewer studies thus far which have expanded LCA to encompass all dimensions of sustainability (Chen and Holden 2017; Schoeneboom et al. 2014; Wu et al. 2014). In some cases, the effects of changing farming practices for environmental impact reduction and animal welfare have simply been identified without a methodology being developed to assess the trade-offs between these impacts (de Boer et al. 2011; Leinonen et al. 2014). This is because, when carrying out SLCAs, most practitioners follow the guidelines that have been
Table 3 Final multivariate models, regarding broiler chicken welfare in Europe, for each dependent variable with at least one independent variable retained from the univariate analysis. The independent variables, their coefficients, standard errors, significance (sig.), and the model fit $\left(R^{2}\right.$ and adjusted $R^{2}\left(R^{2}\right.$ adj.) ) are shown. The country was included in all models as a fixed factor

\begin{tabular}{llllll}
\hline $\begin{array}{l}\text { Welfare indicator } \\
\text { (dependent variable) }\end{array}$ & $\begin{array}{l}\text { Farm characteristic } \\
\text { (independent variable) }\end{array}$ & Coefficient & $\begin{array}{l}\text { Standard } \\
\text { error }\end{array}$ & Sig. $p$ value & $\begin{array}{l}\text { Model fit } R^{2} \\
\left(R^{2} \text { adj. }\right.\end{array}$ \\
\hline Late mortality & Farm age & -0.0149 & 0.00883 & 0.094 & $\begin{array}{l}10.24 \% \\
\text { Country effect }\end{array}$ \\
Carcass condemnation & Flock size & $5.6 \mathrm{E}-05$ & $1.00 \mathrm{E}-05$ & $<0.001$ & $36.75 \%$ \\
& Country effect & & & $<0.001$ & $(35.03 \%)$ \\
Stocking density & Flock size & 0.00037 & $6.30 \mathrm{E}-05$ & $<0.001$ & $36.88 \%$ \\
& Country effect & & & $<0.001$ & $(35.14 \%)$ \\
Overall welfare & Flock size & 0.2464 & 0.0475 & $<0.001$ & $48.20 \%$ \\
& Country effect & & & $<0.001$ & $(46.78 \%)$ \\
\hline
\end{tabular}


Table 4 Animal welfare indicators and overall animal welfare impact (mean values (standard deviation)) in broiler chicken farms in four countries (A, $\mathrm{B}, \mathrm{C}$, and D). The animal welfare impact category was based on $1 \mathrm{~kg}$ of chicken meat production

\begin{tabular}{|c|c|c|c|c|c|c|}
\hline Country & Early mortality (\%) & Late mortality (\%) & Dead on arrival (\%) & $\begin{array}{l}\text { Carcass } \\
\text { condemnations (\%) }\end{array}$ & $\begin{array}{l}\text { Stocking density } \\
\mathrm{kg} / \mathrm{m}^{2}\end{array}$ & $\begin{array}{l}\text { Animal welfare } \\
\text { (mrh eqv.) }\end{array}$ \\
\hline A & $0.69^{\mathrm{a}}$ & $2.84^{\mathrm{a}}$ & $0.17^{\mathrm{b}}$ & $1.61^{\mathrm{a}}$ & $36.6^{\mathrm{a}}$ & $9905^{\mathrm{a}}$ \\
\hline (SD) & $(0.49)$ & (1.59) & $(0.07)$ & $(1.07)$ & $(6.68)$ & (4893) \\
\hline $\mathrm{B}$ & $0.96^{\mathrm{a}, \mathrm{b}}$ & $2.47^{\mathrm{a}, \mathrm{b}}$ & $0.03^{\mathrm{a}}$ & $0.18^{\mathrm{b}}$ & $34.7^{\mathrm{a}}$ & $3857^{\mathrm{b}}$ \\
\hline (SD) & $(0.40)$ & $(1.83)$ & $(0.003)$ & $(0.065)$ & $(3.52)$ & $(2660)$ \\
\hline $\mathrm{C}$ & $1.52^{\mathrm{b}}$ & $4.19^{\mathrm{b}}$ & $0.46^{\mathrm{c}}$ & $1.55^{\mathrm{a}}$ & $35.8^{\mathrm{a}}$ & $19894^{\mathrm{c}}$ \\
\hline (SD) & $(0.43)$ & $(1.04)$ & $(0.18)$ & $(0.28)$ & $(3.13)$ & (2269) \\
\hline $\mathrm{D}$ & $1.21^{\mathrm{b}}$ & $2.79^{a}$ & $0.09^{\mathrm{a}}$ & $0.76^{\mathrm{b}}$ & $44.1^{\mathrm{b}}$ & $9056^{\mathrm{a}}$ \\
\hline (SD) & $(0.27)$ & $(0.67)$ & $(0.02)$ & $(0.25)$ & $(3.72)$ & $(3110)$ \\
\hline
\end{tabular}

Like-for-like superscript letters indicate no significant difference between countries for a given welfare indicator at the 0.05 level

presented by the UNEP-SETAC (2009) Life Cycle Initiative. These guidelines are intrinsically anthropocentric, claiming that the ultimate goal of sustainable development is "human well-being" and making no mention of animals or their welfare. The absence of animal welfare as an impact category in S-LCAs of the agri-food sector excludes potentially significant issues from the assessment process (Regan 1987; Singer 1995, 2013). To address this, a novel framework was developed to account for animal welfare as its own social impact category, which can be assessed in conjunction with the other social impacts outlined by Benoit-Norris et al. (2015) as part of a broader S-LCA study.

Animal welfare is a multi-dimensional concept. This is reflected in the assessment frameworks which have been widely used, such as the Five Freedoms (FAWC 1979, 2009; Webster 2001) or the Four Domains of Welfare Quality (Welfare Quality® 2009). The animal welfare indicators used in this study capture aspects of each of these dimensions but cannot be considered to comprehensively reflect every aspect of welfare. For instance, our methodology did not consider the animals' freedom from hunger and thirst where this had no effect on mortality or carcass rejection rate. The time animals suffer from this state would have to be identified in order for these indicators to be included. Nevertheless, the methodology developed has the capacity to encompass further indicators according to future availability.

The indicators used in this study are all reflective of negative welfare. However, it is now widely accepted that animal welfare cannot simply be based on the absence of negative experiences, but must also include the presence of positive experiences, where life is worth living from the point of view of the animal (Boissy et al. 2007; Mellor 2015). As a way of including positive welfare criteria, assessment should extend to the measurement of environmental enrichment and behavioural expressions of the positive "emotions" of animals, including: play, interaction with enrichment (e.g. perches), exploration, affiliative behaviour, self-grooming, and vocalisations (Bailie et al. 2018; Fontana et al. 2015; Riber et al. 2018). Unfortunately, research is still needed in this area of animal welfare and there are currently no feasible measures indicative of positive welfare that would easily be included in a large-scale S-LCA alongside the negative welfare indicators included in this study. However, the methodology presented here could easily accommodate such positive welfare indicators, if these were to be available to the practitioner. Just as the estimated time the animals were exposed to the negative welfare indicators was multiplied by the risk factor for each indicator, the estimated time the animals are exposed to positive indicators may be multiplied by the "possibility" of the animals being exposed to those conditions. The "possibility" would be the weight factor homologous to the risk level and would be calculated in the same way, based on best and worst practice in a population. In the case of positive welfare, best practice would receive the highest weighting and worst practice would receive the lowest weighting. The total positive welfare could then be subtracted from the overall welfare impact to determine the net welfare of the system. Impact offsetting such as this is already commonplace in LCA (Leinonen et al. 2012; Mackenzie et al. 2015; Williams et al. 2006). Thus, the closer the value of the SHI for animal welfare impact is to 1 , the greater the animal welfare impact of the system; whilst a SHI value $\leq 0$ would indicate that the animals' positive welfare experiences completely compensate for the negative ones.

In the methodology presented in this paper, the welfare indictors received equal weighting for a given risk level, which assumes one dimension of welfare is as important as another. Such a notion is unlikely to hold up to criticism (Fraser 2003). Likewise, if positive welfare indicators were to be incorporated into the methodology, one dimension probably could not fully compensate for another (Botreau et al. 2007b); for instance, good health may not fully compensate for behavioural deprivation. To amend this, scientific evidence, expert opinion, and stakeholder approval of general principles could be sought to refine the weightings $\left(W_{\mathrm{i}}\right)$ in 
the model. The methodology could easily be modified to place greater emphasis on certain indicators over others in the future as understanding on such matters develops.

Human work hours are used to quantify time when determining the value of the social impact categories using the SHDB methodology. However, human work hours are largely irrelevant to the welfare of the livestock; for instance, a farm may employ a lot of staff and have identical values for the animal welfare indicators to another farm that employs fewer staff. The latter farm would seem to have better animal welfare based on the weighted sum methodology of the SHDB, where social impact categories rely on human work hours. To solve this, the animal welfare impact was calculated based on the collective animal work hours. Thus, the methodology presented in this paper acknowledges the fact that, where animals are at an increased risk of negative welfare implications, increased life hours can be worse from a welfare perspective, as it could lead to increased time spent suffering. On the contrary, if positive welfare indicators were to be considered, increased lifespan would improve animal welfare.

Increased flock size resulted in a higher animal welfare impact. There may be a number of contributing factors that account for this. The most obvious explanation is that keeping birds in larger flocks increases infection pressure and decreases the ability of farm workers to spot individual birds displaying signs of reduced welfare and applying appropriate measures to rectify this (Dawkins 2017). The correlation between farm age and flock size suggests that the trend has been to increase the number of birds reared in more recently established buildings compared with older ones. This is reflective of the increasing pressure on farms to become more intensive to meet the demands of a growing global population. More recently constructed buildings may also be more likely to employ technology to monitor animal well-being or other farm conditions. More research is needed to understand the implications of handing more responsibility for animal welfare to machines as we head towards greater application of precision livestock farming systems (Ben Sassi et al. 2016; Wathes 2009; Wathes et al. 2008).

The data used in this study represent a broad range of management practices and thus reveal what constitutes the best and worst animal welfare performance values for each welfare indicator in European systems. S-LCA methodologies that include information on both performance and on geographical contextualization, such as the one presented here, are better positioned to provide an assessment of the social impacts of a system than other approaches highlighted in this study, e.g. stakeholder judgement or comparisons between alternative systems (Russo Garrido et al. 2018). The contribution of a social indicator to the social impact category to which it belongs is determined by the collective risk levels and work hours within the system processes. Hence, this methodology is consistent with efforts of the EU member states to support the livestock sector (Vavra et al. 2015) and, importantly, is intrinsically linked to the functional unit of interest.

Livestock farming is under increasing pressure to become more efficient and more sustainably intensive to meet the demands of a growing global population, whilst there is increasing public concern over standards of farm animal welfare. Hence, we developed a novel and scalable impact category for assessing animal welfare within a S-LCA framework that aligns with this concern. Overall, this study paves the way for practitioners interested in assessing the sustainability of livestock industries holistically.

\section{Conclusions}

A novel framework was presented for assessing animal welfare within an S-LCA, specifically designed to be used in conjunction with the SHDB developed by Benoit-Norris et al. (2015), characterising animal welfare indicators using real farm data from across continental Europe. An aggregation of measures, although not exhaustive, was used to produce an overall assessment of animal welfare. The SHDB is also a useful methodology for identifying the social hotspots of a system; this was illustrated by the case study of four European countries. Animal welfare is only one issue in a broad range of social issues that result from the agri-food sector but until recently it has received the least attention. Other social issues associated with the food supply chain include but are not limited to the following: labour rights and decent work, health and safety, human rights, governance, and community infrastructure. The methodology presented here allows animal welfare to be measured alongside these other important social impact categories. Thus, this study provides a basis for discussion that will ultimately further the development of S-LCA, animal welfare assessment, and lead to the mitigation of animal welfare impact in future livestock systems.

Acknowledgements We would like to thank David Speller from Applied Group for his expert input.

Funding information This research was made possible by a Doctoral Training Award from Newcastle University to C.W. Tallentire. The data used for testing the framework were collected under the PROHEALTH project. PROHEALTH received funding from the European Union 7th Framework Programme for Research, Technological Development, and Demonstration under grant agreement $\mathrm{n}^{\circ} 613574$.

\section{Compliance with ethical standards}

Conflicts of interest The authors declare that they have no conflict of interest.

Open Access This article is distributed under the terms of the Creative Commons Attribution 4.0 International License (http:// 
creativecommons.org/licenses/by/4.0/), which permits unrestricted use, distribution, and reproduction in any medium, provided you give appropriate credit to the original author(s) and the source, provide a link to the Creative Commons license, and indicate if changes were made.

Publisher's Note Springer Nature remains neutral with regard to jurisdictional claims in published maps and institutional affiliations.

\section{References}

Alexandratos N, Bruinsma J (2012) World agriculture towards 2030/2050: the 2012 revision. ESA working paper. FAO, Rome

Allain V, Mirabito L, Arnould C, Colas M, Le Bouquin S, Lupo C, Michel V (2009) Skin lesions in broiler chickens measured at the slaughterhouse: relationships between lesions and between their prevalence and rearing factors. Brit Poultry Sci 50:407-417

Bailie CL, Baxter M, O'Connell NE (2018) Exploring perch provision options for commercial broiler chickens. Appl Anim Behav Sci 200: 114-122

Ben Sassi N, Averós X, Estevez I (2016) Technology and poultry welfare. Animals 6:62

Benoit-Norris C et al (2010) The guidelines for social life cycle assessment of products: just in time! Int J Life Cycle Assess 15:156-163

Benoît-Norris C, Vickery-Niederman G, Valdivia S, Franze J, Traverso M, Ciroth A, Mazijn B (2011) Introducing the UNEP/SETAC methodological sheets for subcategories of social LCA. Int J Life Cycle Assess 16:682-690

Benoît-Norris C, Cavan DA, Norris G (2012) Identifying social impacts in product supply chains: overview and application of the social hotspot database. Sustainability 4:1946-1965

Benoît-Norris C, Norris G, Aulisio D (2014) Efficient assessment of social hotspots in the supply chains of 100 product categories using the Social Hotspots Database. Sustainability 6:6973-6984

Benoît-Norris C, Norris GA, Aulisio Cavan D (2015) Social Hotspots Database: supporting documentation

Bessei W (2006) Welfare of broilers: a review. World Poultry Sci J 62: 455-466

Boissy A, Manteuffel G, Jensen MB, Moe RO, Spruijt B, Keeling LJ, Winckler C, Forkman B, Dimitrov I, Langbein J, Bakken M, Veissier I, Aubert A (2007) Assessment of positive emotions in animals to improve their welfare. Physiol Behav 92:375-397

Bokkers EAM, de Boer IJM (2009) Economic, ecological, and social performance of conventional and organic broiler production in the Netherlands. Brit Poultry Sci 50:546-557

Bokkers E, De Boer I, Koene P (2011) Space needs of broilers. Anim Welf 20:623-632

Botreau R, Bonde M, Butterworth A, Perny P, Bracke M, Capdeville J, Veissier I (2007a) Aggregation of measures to produce an overall assessment of animal welfare. Part 1: a review of existing methods. Animal 1:1179-1187

Botreau R, Bracke M, Perny P, Butterworth A, Capdeville J, Van Reenen C, Veissier I (2007b) Aggregation of measures to produce an overall assessment of animal welfare. Part 2: analysis of constraints. Animal 1: 1188-1197

Broom DM (2010) Animal welfare: an aspect of care, sustainability, and food quality required by the public. J Vet Med Educ 37:83-88

Broom DM, Galindo FA, Murgueitio E (2013) Sustainable, efficient livestock production with high biodiversity and good welfare for animals. P R Soc B 280:2013-2025

Buijs S, Keeling LJ, Tuyttens FAM (2011) Using motivation to feed as a way to assess the importance of space for broiler chickens. Anim Behav 81:145-151
Buyse J, Simons PCM, Boshouwers FMG, Decuypere E (2007) Effect of intermittent lighting, light intensity and source on the performance and welfare of broilers. World Poultry Sci J 52:121-130

Carenzi C, Verga M (2009) Animal welfare: review of the scientific concept and definition. Ital J Anim Sci 8:21-30

Castellini C, Boggia A, Cortina C, Dal Bosco A, Paolotti L, Novelli E, Mugnai C (2012) A multicriteria approach for measuring the sustainability of different poultry production systems. J Clean Prod 37:192-201

Chan KM (2011) Ethical extensionism under uncertainty of sentience: duties to non-human organisms without drawing a line. Environ Value 20:323-346

Chauvin C, Hillion S, Balaine L, Michel V, Peraste J, Petetin I, Lupo C, le Bouquin S (2011) Factors associated with mortality of broilers during transport to slaughterhouse. Animal 5:287-293

Chen W, Holden NM (2017) Social life cycle assessment of average Irish dairy farm. Int J Life Cycle Ass 22:1459-1472

Clark B, Stewart GB, Panzone LA, Kyriazakis I, Frewer LJ (2016) A systematic review of public attitudes, perceptions and Behaviours towards production diseases associated with farm animal welfare. $\mathrm{J}$ Agric Environ Ethics 29:455-478

Compassion in World Farming (2013) The life of: broiler chickens. https://www.ciwf.org.uk/media/5235306/The-life-of-Broilerchickens.pdf. Accessed 16 June 2016

Compassion in World Farming (2017) Higher welfare for meat chickens. https://www.ciwf.org.uk/farm-animals/chickens/meat-chickens/ higher-welfare-alternatives/. Accessed 17 February 2017

Dawkins MS (1990) From an animal's point of view: motivation, fitness, and animal welfare. Behav Brain Sci 13:1-9

Dawkins MS (2017) Animal welfare and efficient farming: is conflict inevitable? Anim Prod Sci 57:201-208

de Boer IJM, Cederberg C, Eady S, Gollnow S, Kristensen T, Macleod M, Meul M, Nemecek T, Phong LT, Thoma G, van der Werf H, Williams AG, Zonderland-Thomassen MA (2011) Greenhouse gas mitigation in animal production: towards an integrated life cycle sustainability assessment. Curr Opin Env Sust 3:423-431

de Jonge J, van Trijp HCM (2013) The impact of broiler production system practices on consumer perceptions of animal welfare. Poultry Sci 92:3080-3095

Del Prado A et al (2011) SIMSDAIRY: a modelling framework to identify sustainable dairy farms in the UK. Framework description and test for organic systems and $\mathrm{N}$ fertiliser optimisation. Sci Total Environ 409:3993-4009

Dolman MA, Sonneveld MPW, Mollenhorst H, de Boer IJM (2014) Benchmarking the economic, environmental and societal performance of Dutch dairy farms aiming at internal recycling of nutrients. J Clean Prod 73:245-252

EFSA Panel on Animal Health and Welfare (2010) Scientific opinion on the influence of genetic parameters on the welfare and the resistance to stress of commercial broilers. EFSA J 8. https://doi.org/10.2903/j. efsa.2010.1666

European Commission (2005) Attitudes of consumers towards the welfare of farmed animals. General Health and Consumer Protection, Special Eurobarometer 229:45

European Commission (2007) European Union, Council Directive 2007/43/EC laying down minimum rules for the protection of chickens kept for meat production

European Commission (2017) Study on the application of the broilers directive (DIR 2007/43/EC) and development of welfare indicators. Directorate-General for Health and Food Safety, Luxembourg

European Commission (2018) Report from the commission to the european parliament and the council on the application of Directive 2007/43/EC and its influence on the welfare of chickens kept for meat production, as well as the development of welfare indicators. Directorate-General for Health and Food Safety, Belgium

FAO (2016) Sources of meat. http://www.fao.org/ag/againfo/themes/en/ meat/backgr_sources.html. Accessed 29 May 2016 
FAWC (1979) Farm Animal Welfare Council-press statement. http:// webarchive.nationalarchives.gov.uk/20121010012428/http:/www. fawc.org.uk/pdf/fivefreedoms1979.pdf. Accessed 14 May 2018

FAWC (2009) Farm animal welfare in Great Britain: past, present and future. http://webarchive.nationalarchives.gov.uk/ 20120802220725/http://www.fawc.org.uk/pdf/ppf-report091012. pdf. Accessed 23 April 2018

Fontana I, Tullo E, Scrase A, Butterworth A (2015) Vocalisation sound pattern identification in young broiler chickens. Animal 10:15671574

Fraser D (2003) Assessing animal welfare at the farm and group level: the interplay of science and values. Anim Welf 12:433-443

Fraser D, Duncan IJH, Edwards SA, Grandin T, Gregory NG, Guyonnet V, Hemsworth PH, Huertas SM, Huzzey JM, Mellor DJ, Mench JA, Špinka M, Whay HR (2013) General principles for the welfare of animals in production systems: the underlying science and its application. Vet J 198:19-27

Gocsik É, Silvera A, Hansson H, Saatkamp H, Blokhuis H (2017) Exploring the economic potential of reducing broiler lameness. Brit Poultry Sci 58:337-347

Gouveia K, Vaz-Pires P, da Costa PM (2009) Welfare assessment of broilers through examination of haematomas, foot-pad dermatitis, scratches and breast blisters at processing. Anim Welf 18:43-48

Gremmen B, Bruijnis MRN, Blok V, Stassen EN (2018) A public survey on handling male chicks in the Dutch egg sector. J Agric Environ Ethics 31:93-107

Haslam SM, Knowles TG, Brown SN, Wilkins LJ, Kestin SC, Warriss PD, Nicol CJ (2008) Prevalence and factors associated with it, of birds dead on arrival at the slaughterhouse and other rejection conditions in broiler chickens. Brit Poultry Sci 49:685-696

Head M, Sevenster M, Odegard I, Krutwagen B, Croezen H, Bergsma G (2014) Life cycle impacts of protein-rich foods: creating robust yet extensive life cycle models for use in a consumer app. J Clean Prod $73: 165-174$

Huneau-Salaün A, Stärk KDC, Mateus A, Lupo C, Lindberg A, Le Bouquin-Leneveu S (2014) Contribution of meat inspection to the surveillance of poultry health and welfare in the European Union. Epidemiol Infect 143:2459-2472

Jacobs L, Delezie E, Duchateau L, Goethals K, Tuyttens FAM (2017) Broiler chickens dead on arrival: associated risk factors and welfare indicators. Poultry Sci 96:259-265

Kearney J (2010) Food consumption trends and drivers. Philos T R SOC B 365:2793-2807

Kittelsen KE, Granquist EG, Kolbjørnsen Ø, Nafstad O, Moe RO (2015) A comparison of post-mortem findings in broilers dead-on-farm and broilers dead-on-arrival at the abattoir. Poultry Sci 94:2622-2629

Lamey A (2007) Food fight! Davis versus Regan on the ethics of eating beef. J Soc Philos 38:331-348

Leinonen I, Williams AG, Wiseman J, Guy J, Kyriazakis I (2012) Predicting the environmental impacts of chicken systems in the UK through a life cycle assessment: broiler production systems. Poultry Sci 91:8-25

Leinonen I, Williams AG, Kyriazakis I (2014) The effects of welfareenhancing system changes on the environmental impacts of broiler and egg production. Poultry Sci 93:256-266

Llonch P, Lawrence A, Haskell M, Blanco-Penedo I, Turner S (2015) The need for a quantitative assessment of animal welfare trade-offs in climate change mitigation scenarios. Adv Anim Biosci 6:9-11

Lupo C, Chauvin C, Balaine L, Petetin I, Péraste J, Colin P, Le Bouquin S (2008) Postmortem condemnations of processed broiler chickens in western France. Vet Rec 162:709-713

Mackenzie SG, Leinonen I, Ferguson N, Kyriazakis I (2015) Accounting for uncertainty in the quantification of the environmental impacts of Canadian pig farming systems. J Anim Sci 93:3130-3143
McLean JA, Savory C, Sparks N (2002) Welfare of male and female broiler chickens in relation to stocking density, as indicated by performance, health and behaviour. Anim Welf 11:55-74

Mellor DJ (2015) Positive animal welfare states and reference standards for welfare assessment. New Zeal Vet J 63:17-23

Meul M, Van Passel S, Fremaut D, Haesaert G (2012) Higher sustainability performance of intensive grazing versus zero-grazing dairy systems. Agron Sustain Dev 32:629-638

Müller-Lindenlauf M, Deittert C, Köpke U (2010) Assessment of environmental effects, animal welfare and milk quality among organic dairy farms. Livest Sci 128:140-148

Neugebauer S, Fischer D, Bach V, Finkbeiner M (2014) Social indicators for meat production-addressing workers, local com-munities, consumers and animals. In: Proceedings of 9th International Conference LCA of Food San Francisco, California. In: USA 8-10 October

Nijdam E, Zailan AR, van Eck JH, Decuypere E, Stegeman JA (2006) Pathological features in dead on arrival broilers with special reference to heart disorders. Poultry Sci 85:1303-1308

Notarnicola B, Sala S, Anton A, McLaren SJ, Saouter E, Sonesson U (2017) The role of life cycle assessment in supporting sustainable agri-food systems: a review of the challenges. J Clean Prod 140: 399-409

Pelletier N, Ustaoglu E, Benoit C, Norris G, Rosenbaum E, Vasta A, Sala S (2018) Social sustainability in trade and development policy. Int J Life Cycle Assess 23:629-639

Petracci M, Bianchi M, Cavani C, Gaspari P, Lavazza A (2006) Preslaughter mortality in broiler chickens, turkeys, and spent hens under commercial slaughtering. Poultry Sci 85:1660-1664

Regan T (1987) The case for animal rights. In: Advances in animal welfare science 1986/87. Springer, pp 179-189

Revéret J-P, Couture J-M, Parent J (2015) Socioeconomic LCA of milk production in Canada. In: Muthu SS (ed) Social life cycle assessment: an insight. Springer, Singapore, pp 25-69. https://doi.org/10. 1007/978-981-287-296-8_2

Riber AB, van de Weerd HA, de Jong IC, Steenfeldt S (2018) Review of environmental enrichment for broiler chickens. Poultry Sci 97:378 396

Russo Garrido S, Parent J, Beaulieu L, Revéret J-P (2018) A literature review of type I SLCA - making the logic underlying methodological choices explicit. Int J Life Cycle Assess 23:432-444

Scherer L, Tomasik B, Rueda O, Pfister S (2018) Framework for integrating animal welfare into life cycle sustainability assessment. Int J Life Cycle Assess 23:1476-1490

Schoeneboom J, Carton S, Hosotte V, Frank M, Saling P, Rehl T (2014) Life cycle sustainability assessment of dairy farming at the Grignon farm. In: Proceedings of the 9th International Conference on Life Cycle Assessment in the Agri-Food Sector (LCA Food 2014), San Francisco, California, USA, 8-10 October

Singer P (1995) Animal liberation. Random House, UK

Singer P (2013) In defense of animals: the second wave. Blackwell Publishing, UK

Te Velde H, Aarts N, Van Woerkum C (2002) Dealing with ambivalence: farmers' and consumers' perceptions of animal welfare in livestock breeding. J Agric Environ Ethics 15:203-219

Thomas DG, Son J-H, Ravindran V, Thomas DV (2011) The effect of stocking density on the behaviour of broiler chickens. Korean J Poult Sci 38:1-4

UNEP-SETAC (2009) Guidelines for social life cycle assessment of products. United Nations Environment Programme, Paris

van Asselt ED, Capuano E, van der Fels-Klerx HJ (2015) Sustainability of milk production in the Netherlands - a comparison between raw organic, pasteurised organic and conventional milk. Int Dairy J 47: $19-26$

Van Limbergen T et al (2018) Scoring biosecurity in European conventional broiler production. Poultry Sci 97:74-83 
Varner GE (2002) In nature's interests?: interests, animal rights, and environmental ethics. Oxford University Press, USA

Vavra J, Munzarova S, Bednarikova M (2015) Assessment of social impacts of chemical and food products in the Czech Republic. In: Muthu SS (ed) Social life cycle assessment. Environmental footprints and eco-design of products and processes. Springer, Singapore

Wathes C (2009) Precision livestock farming for animal health, welfare and production sustainable animal production: the challenges and potential developments for professional farming. Wageningen Academic Publishers, The Netherlands, pp 411-420

Wathes C (2010) Lives worth living? Vet Rec 166:468-469

Wathes CM, Kristensen HH, Aerts JM, Berckmans D (2008) Is precision livestock farming an engineer's daydream or nightmare, an animal's friend or foe, and a farmer's panacea or pitfall? Comput Electron Agric 64:2-10
Webster AJF (2001) Farm animal welfare: the five freedoms and the free market. Vet J 161:229-237

Welfare Quality ${ }^{\circledR}(2009)$ Welfare Quality ${ }^{\circledR}$ assessment protocol for poultry (broilers, laying hens). Welfare Quality ${ }^{\circledR}$ Consortium, Lelystad, the Netherlands, p 113

Williams AG, Audsley E, Sandars DL (2006) Determining the environmental burdens and resource use in the production of agricultural and horticultural commodities. Cranfield University and Defra, Bedford, UK

Wu R, Yang D, Chen J (2014) Social life cycle assessment revisited. Sustainability 6:4200-4226

Zucali M, Battelli G, Battini M, Bava L, Decimo M, Mattiello S, Povolo M, Brasca M (2016) Multi-dimensional assessment and scoring system for dairy farms. Ital J Anim Sci 15:492-503 